\title{
CERTIFICAÇÃO PARTICIPATIVA E AGROECOLOGIA: PROCESSOS DE ORGANIZAÇÃO E RESISTÊNCIA CAMPONESA NA MATA PARAIBANA
}

\section{CERTIFICACIÓN PARTICIPATIVA Y AGROECOLOGÍA: PROCESOS DE ORGANIZACIÓN Y RESISTENCIA CAMPESINA EN LA MATA \\ PARAIBANA.}

\begin{abstract}
PARTICIPATIVE CERTIFICATION AND AGROECOLOGY: PROCESS OF ORGANIZATION AND PEASANT RESISTANCE IN "MATA PARAIBANA"
\end{abstract}

\section{Mariana Borba de Oliveira ${ }^{1}$}

\begin{abstract}
RESUMO: A temática deste artigo trata da resistência do campesinato paraibano à agricultura capitalista. Interpretamos uma organização camponesa cuja produção é de base agroecológica e a comercialização dos produtos, realizada diretamente com o consumidor, como uma forte estratégia que permite a (re) construção das bases da produção camponesa, e norteia o paradigma do desenvolvimento local sustentável. A experiência estudada é a Feira Agroecológica que acontece em João Pessoa (PB), no campus I da Universidade Federal da Paraíba (UFPB), e que comercializa produtos de quatro assentamentos rurais localizados na Várzea do rio Paraíba (nos municípios de Cruz do Espírito Santo, Sapé e Sobrado), e um assentamento rural localizado no litoral sul da Paraíba (município do Conde). Investigamos a hipótese do projeto da Feira ser fortalecido por uma certificação participativa da produção. A pesquisa comprova o fortalecimento do projeto através da certificação, cuja metodologia foi construída a partir de um processo participativo de controle da produção que envolve produtores, consumidores, técnicos, poder público e sociedade civil.
\end{abstract}

Palavras Chave: Campesinato - Resistência - Desenvolvimento Local Agroecologia - Certificação Participativa

1 Mestre em Geografia pela Universidade Federal da Paraíba (UFPB) marianageoufpb@hotmail.com 
RESUMEN: El tema de la investigación aborda la resistencia campesina frente a la agricultura capitalista. Se comprehende la organización campesina de producción agroecológica y la comercialización de los productos hecha directamente con el consumidor en la feria, como una fuerte estrategia de resistencia que permite la (re) construcción de las bases de producción campesina, y la construcción de paradigmas de desarrollo local sostenible. El estudio de caso es la Feria Agroecológica que ocurre en la cuidad de João Pessoa (PB), en el campus I de la Universidade Federal da Paraíba (UFPB), en este sitio hay un mercado de horticulturas con productos cultivados por cuatro asentamientos rurales ubicados en las llanuras de inundación del río Paraíba (en los municipios Cruz do Espírito Santo, Sapé y Sobrado), y otro situado en el litoral sur del estado de Paraíba (municipio Conde). Los resultados muestran el fortalecimiento del proyecto de la Feria por medio de la certificación, y que esto ocurre por el empleo de la metodología que fue desarrollada dentro de un proceso participativo de control da la producción de los productos, consumidor, técnicos, poder público y la sociedad civil.

Palabras Clave: Campesinado - Resistencia - Desarrollo Local - Agroecología

- Certificación Participativa

ABSTRACT: The topic approached by this research is the rural resistance against capitalist agriculture. We analyze a peasant organization whose production is agroecologic and the commercialization of the products is done directly to the consumers as a strong strategy of resistance that allows the (re)construction of the basis of the rural reproduction and the construction of new paradigms of sustainability. The experience studied is the Agroecologic Fair that take place in João Pessoa (PB), in the campus I of the Universidade Federal da Paraíba (UFPB), that commercialize products coming from four rural settlements located alongside the Paraiba river, in the districts of Cruz do Espírito Santo, Sapé and Sobrado, and a rural settlement located in the South Coast of the state of Paraiba - district of Conde. We observed the strengthening of the Fair by the use of a certification project, granted to the agroecologic products through a common effort of production control that involves producers, consumers, technicians, government and civil society.

Key Words: Peasant - Resistance - Local Development - Agroecology Participative Certification 


\section{INTRODUÇÃO}

Este artigo sintetiza os resultados de pesquisa de mestrado stricto sensu vinculada à Universidade Federal da Paraíba (UFPB) ${ }^{2}$ no âmbito da linha de pesquisa Cidade e Campo: espaço e trabalho. O trabalho abordou estratégias de resistência do campesinato paraibano à agricultura capitalista, como a produção agroecológica, a venda direta desses produtos através de feiras, os intercâmbios produtivos, a inserção política dos camponeses no cenário da agricultura familiar e a certificação participativa. Entende-se que essas iniciativas são responsáveis por fomentar uma autonomia camponesa relativa, que por sua vez, gera um desenvolvimento local sustentável no campo, e a oferta de produtos livres de agrotóxico à cidade.

A pesquisa analisou a metodologia da certificação participativa (ou certificação social) de produtos agroecológicos e sua relação pode fortalecer o projeto da Agroecologia e das Feiras. O diferencial dessa certificação advém da organização social - da produção à comercialização - , necessária para a concretização do processo, pautado na confiança e no controle social da qualidade orgânica, garantindo ao consumidor algo muito além da certeza de estar adquirindo um produto isento de contaminação química. Garante, também, que o produto comercializado seja resultado de uma agricultura que se preocupa com a preservação do meio ambiente, com a qualidade nutricional dos alimentos e com o retorno econômico para o homem do campo, sendo essencial a qualidade de vida para quem vive no campo e nas cidades.

A experiência que trazemos como estudo de caso é desenvolvida pela Associação dos Agricultores(as) Agroecológicos da Várzea Paraibana (Ecovárzea), uma organização camponesa cujos sujeitos são assentados da reforma agrária, produzem a partir dos princípios da agroecologia e comercializam seus produtos diretamente com o consumidor através de

\footnotetext{
${ }^{2}$ A pesquisa contou com auxílio financeiro da Coordenação de Aperfeiçoamento de Pessoal de Nível Superior (Capes) através de bolsa de pesquisa e foi orientada pela Professora Doutora Maria de Fátima Ferreira Rodrigues.
} 
uma Feira Agroecológica. A Ecovárzea pratica há mais de dez anos os propósitos da sustentabilidade e da resistência camponesa, e desempenha um papel fundamental na melhoria da qualidade de vida de aproximadamente 30 famílias assentadas, bem como da comunidade consumidora que se beneficia da sua produção. A Feira Agroecológica acontece desde 2001 no Campus I da Universidade Federal da Paraíba (UFPB), todas as sextas-feiras, sendo a Ecovárzea uma das organizações pioneiras na Paraíba a implantar o processo de produção agroecológica e venda direta ao consumidor.

A história da criação das Feiras está relacionada à própria história de luta e resistência dos sujeitos envolvidos nesse projeto, iniciada nas reivindicações e estratégias de pressão para a desapropriação das terras improdutivas, e na reflexão política da função social da terra dos assentamentos, ambos os processos conduzidos pela Comissão Pastoral da Terra (CPT). Assim, o processo de organização da Feira da UFPB nasce depois dos camponeses conseguirem a terra onde trabalhar e viver, e remete às discussões acerca da necessidade dos camponeses recémassentados desfazerem os laços de dependência com os atravessadores na comercialização de seus produtos, e também à necessidade de se assegurar a Soberania Alimentar do núcleo familiar (MARCOS, 2005). A região da Mata Paraibana foi palco das primeiras discussões realizadas, e o projeto que se iniciou no Litoral da Paraíba foi multiplicado por todo o território do Estado, com organizações não governamentais (ONGs) e poder público a apoiar esses empreendimentos, que atualmente perfazem 22 experiências numa escala geográfica que se estende do Litoral até o Sertão da Paraíba. No mapa 1, estão identificados os municípios que possuem Feiras Agroecológicas na Paraíba. 


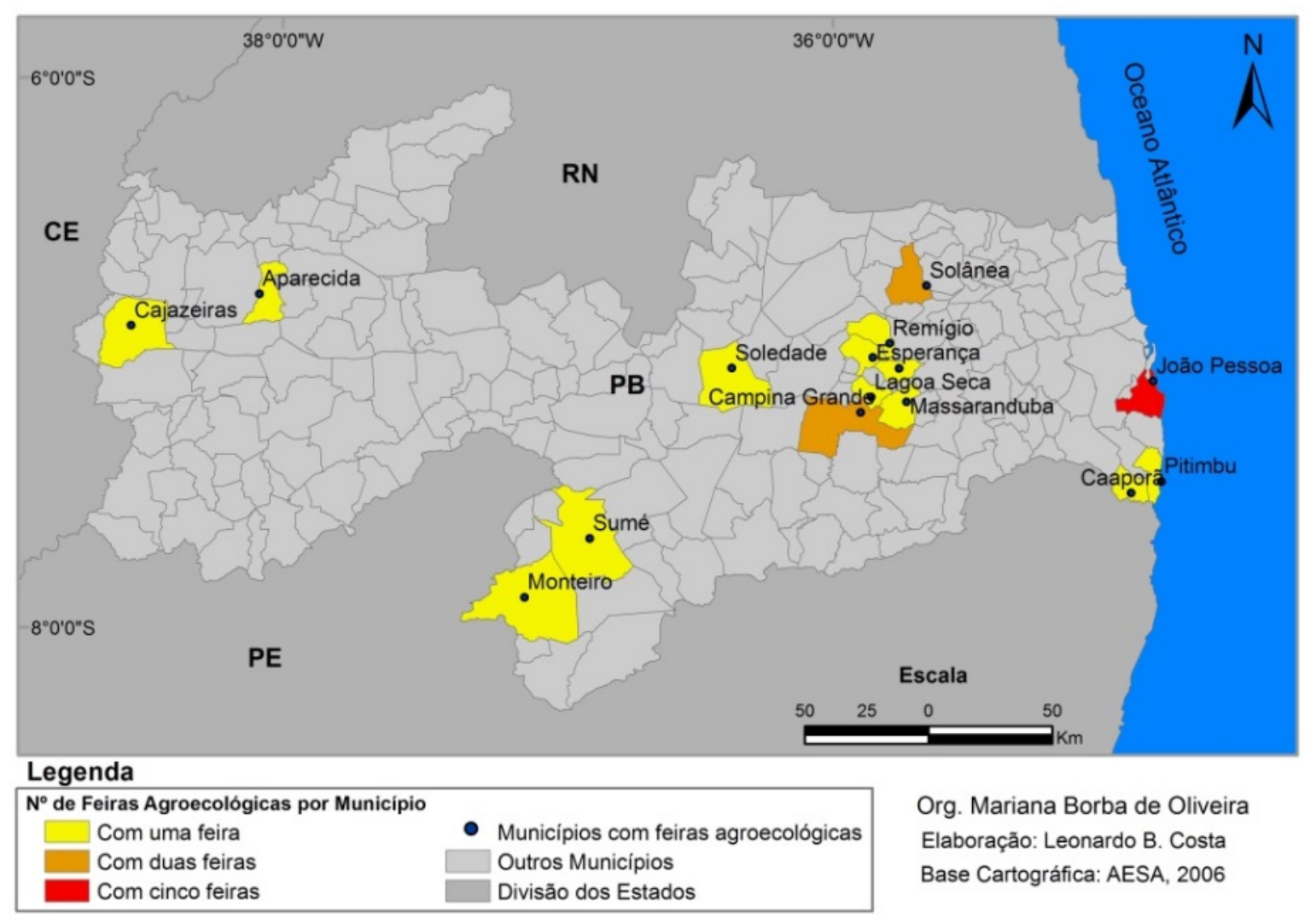

MAPA 1: Municípios da Paraíba com Feiras Agroecológicas.

Os camponeses responsáveis pela Feira são provenientes dos assentamentos rurais Dona Antônia (município do Conde); Dona Helena (município de Cruz do Espírito Santo); Padre Gino, Rainha dos Anjos e Boa Vista (município de Sapé); 21 de Abril (município de Marí) e o acampamento Ponta de Gramame (município de João Pessoa). No mapa 2, vê-se a representação do fluxo da comercialização. 


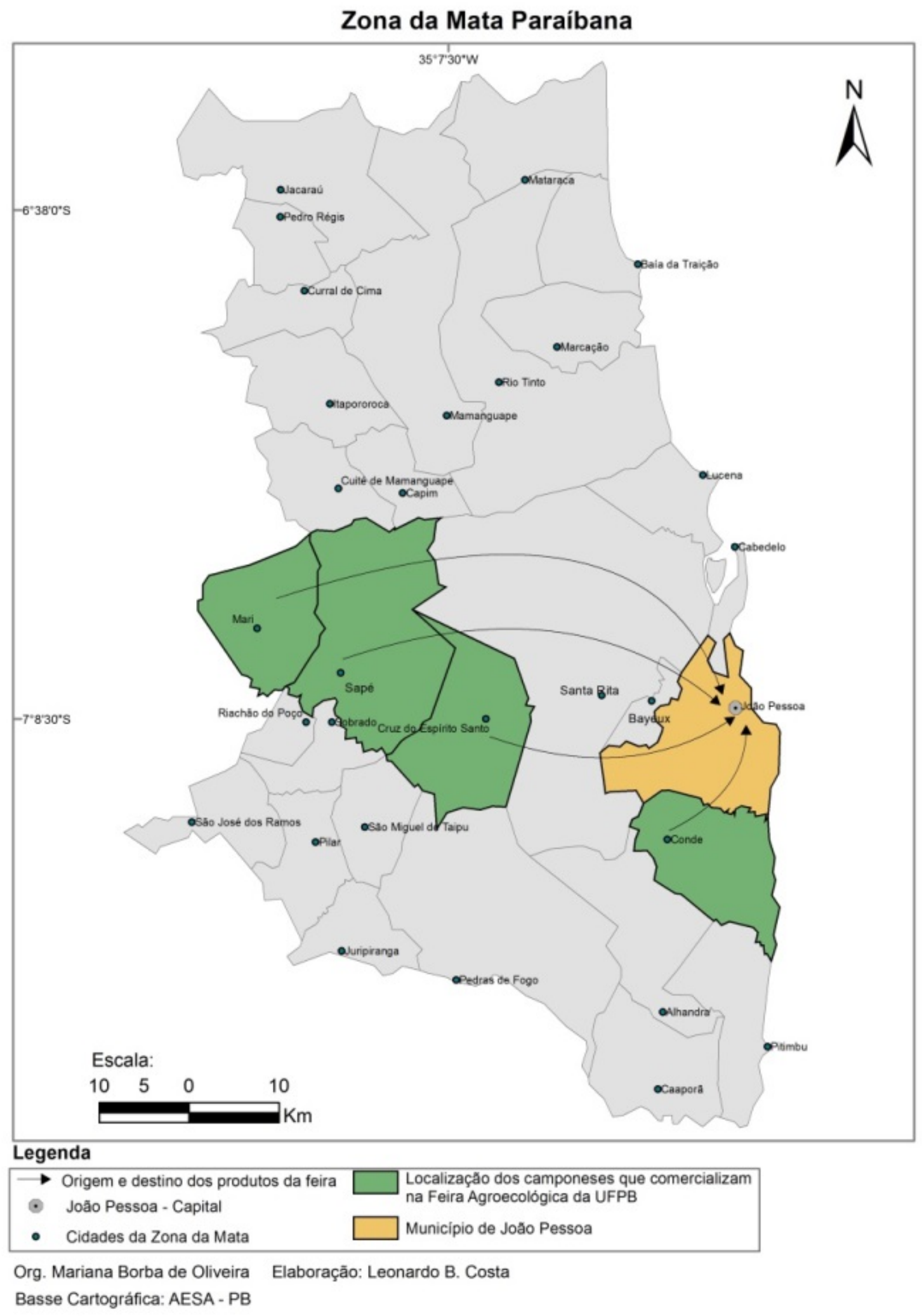

Mapa 2: Origem municipal dos Produtos da Feira da UFPB. 


\section{A FEIRA AGROECOLÓGICA DA UFPB: RESISTÊNCIA AO CAPITALISMO AGRÍCOLA DA MATA PARAIBANA}

Torna-se imprescindível caracterizar brevemente as contradições territoriais da Mata Paraibana para justificar que a Feira Agroecológica promovida pela Ecovárzea seja considerada uma estratégia de resistência e de reprodução camponesa. Nossa abordagem dialoga com a percepção encontrada em autores que fundamentam seus argumentos na tradição marxista a exemplo de Martins (1981, 2010), Oliveira (1990, 2007), Fernandes (1996) e Paulino e Almeida (2010), e que defendem a necessidade de um novo arranjo territorial para o espaço agrário brasileiro, através da reforma agrária e da valorização da territorialidade camponesa. Nesta perspectiva, entendemos que a produção do espaço no campo brasileiro gera um cenário socioambiental perverso de dominação, expropriação, exploração e degradação por parte dos capitalistas e do latifúndio, e de resistência por parte dos trabalhadores e camponeses ${ }^{3}$.

A elevada importância dada à função agrícola, sobretudo após a Revolução Verde, aprimora o esquema de enriquecimento da elite agrária brasileira que se beneficia tanto da renda do latifúndio improdutivo quanto da produtividade das monoculturas para exportação. Portanto, o poder daqueles que detêm a propriedade da terra e os meios de produção territorializa o espaço agrário a partir da dominação do meio natural e da subordinação da força de trabalho, existindo uma relação desigual entre capital e trabalho. Tal relação valoriza a acumulação capitalista e despreza a dimensão humana e ambiental, pois considera o desenvolvimento rural como sinônimo do desenvolvimento agrícola, promovendo uma agricultura puramente capitalista, produtora de commodities para o mercado externo. Assim, a história da agricultura brasileira é marcada desde o início por uma opção pela agricultura comercial em detrimento da agricultura camponesa (MARTINS, 1981; OLIVEIRA, 1990; 2007).

\footnotetext{
${ }^{3}$ No contexto da pesquisa, são considerados trabalhadores os sujeitos assalariados das atividades do campo, e camponeses aqueles que usam a terra para a reprodução do núcleo familiar, a partir de uma relação harmônica com a natureza, tendo ou não a propriedade da terra.
} 
Assim, a territorialização da Mata Paraibana não difere substancialmente de todo contexto da formação do espaço agrário brasileiro, sendo marcada pela imposição do poder econômico do capital canavieiro, que, de maneira geral, devasta o bioma da Mata Atlântica e subordina a população do campo, índios e camponeses, expropriando-os da terra de trabalho, sujeitando-os ao assalariamento no corte da cana e à migração para os centros urbanos. O processo de colonização, a política de concentração de terras, os incentivos estatais à expansão do capitalismo no campo são as forças de opressão contra as quais o campesinato resiste há séculos. Galeano (1988, p. 74- 75) nos lembra das práticas e manejos predatórios instalados na Mata Paraibana, e afirma:

O açúcar arrasou o Nordeste. A faixa úmida do Litoral, bem regada por chuvas, tinha um solo de grande fertilidade, muito rico em húmus e sais minerais, coberto por matas tropicais, da Bahia até o Ceará. Esta região de matas tropicais converteu-se, como diz Josué de Castro ${ }^{4}$, em regiões de savanas. Naturalmente nascida para produzir alimentos, passou a ser uma região de fome. Onde tudo germinava com exuberante vigor, o latifúndio açucareiro, destrutivo e avassalador, deixou rochas estéreis, solos lavados, terras erodidas [...]. A abundância e prosperidade eram, como de costume, simétricas à miséria da maioria da população, que vivia em estado crônico de desnutrição.

Warren Dean, estudioso americano considerado um brasilianista, também destaca a devastação dos recursos naturais, e se refere criticamente aos exploradores como invasores. O autor relata que:

[...] a Mata Atlântica propiciou lucros fáceis: papagaios, corantes, escravos, ouro, ipecacuanha, orquídea e madeira para proveito de seus senhores coloniais, e queimada e devastada, uma camada imensamente fértil de cinzas que possibilitou uma agricultura passiva, imprudente e insustentável (DEAN, 2002, p.380).

Essa realidade se agrava com o surgimento das primeiras usinas de açúcar no Nordeste, que datam de 1885 em Pernambuco (ANDRADE, 1986)

\footnotetext{
${ }^{4} \mathrm{O}$ autor se refere à obra Geografia da Fome, de Josué de Castro (1963).
} 
e 1910 na Paraíba (MOREIRA e TARGINO, 1997), e são criadas em substituição aos antigos engenhos - cujo ápice se deu entre as décadas de 1910 e 1950 - através dos investimentos para a industrialização brasileira. As usinas intensificam o avanço do capital em direção ao território camponês, ocupando os sítios dos moradores - áreas até então destinadas ao plantio da roça para auto consumo. As medidas protecionistas do governo em favor dos usineiros nordestinos, após a queda do valor do açúcar ocasionada pela forte industrialização do Centro-Sul, que passou a plantar cana e concorrer com o Nordeste, levou ao agravamento deste quadro de injustiça (ANDRADE, 1986).

Podemos destacar como os principais incentivos às usinas de cana-deaçúcar: a criação do Instituto do Açúcar e do Álcool (IAA), em 1933, que estabeleceu quotas de produção para diferentes estados da federação brasileira, na tentativa de igualar a produção do Nordeste à do Centro-Sul do país; a criação da Superintendência de Desenvolvimento do Nordeste (Sudene), em 1959, na tentativa de reverter o quadro de desigualdades regionais, promovendo a industrialização do Nordeste e o combate à seca; e os incentivos do Proálcool, na década de 1970, política desenvolvida pelo Governo Federal visando substituir o petróleo pelo álcool nos combustíveis, e conceder empréstimos de alto valor com prazos extensos para os empresários que se dispusessem a investir em destilarias (OLIVEIRA, 2006). Ao se referir às contradições do Proálcool na Paraíba, Moreira e Targino (1997, p. 113) afirmam que:

[...] a riqueza produzida pela expansão da cana e pelo apogeu do PROÁLCOOL, infelizmente não chegou à mesa da classe trabalhadora [...]. A expulsão - expropriação dos pequenos trabalhadores de subsistência (moradores, parceiros, foreiros) foi constatada tanto nas áreas tradicionais produtoras de cana, como naquelas que foram por ela incorporadas mais recentemente. O resultado foi, de um lado, o esvaziamento demográfico da zona rural e, de outro, o aumento das tensões sociais no campo, nas áreas onde a resistência camponesa sobrepujou a força do capital.

É importante lembrar que na medida em que o capital avança no espaço rural, trazendo consigo as desigualdades territoriais, ele preceitua 
uma organização social dos oprimidos. Essa organização é perceptível principalmente pelo surgimento de movimentos e organizações sociais que lutam em prol da reforma agrária, da função social da terra, da soberania alimentar, da produção agroecológica e da comercialização alternativa.

Para Oliveira (2007), esses movimentos e organizações demonstram a capacidade de resistência e de construção social dos expropriados pelo capital e que os acampamentos e assentamentos rurais são formas de luta pelo direito à terra livre e ao trabalho liberto. O autor afirma que

\footnotetext{
É a terra que vai permitir aos trabalhadores - donos do tempo que o capital roubou e construtores do território comunitário e/ou coletivo que o espaço do capital não conseguiu reter à bala ou por pressão - reporemse/reproduzirem-se, no seio do território da reprodução geral capitalista (OLIVEIRA, 2007, p. 137).
}

Diante do conteúdo exposto, indagamos: Será possível superar a lógica produtivista do capitalismo agrícola? Podemos dizer que as resistências encontradas estão inseridas numa mudança paradigmática de produção e consumo? Tentaremos responder a essas questões a partir da interlocução com os preceitos da agroecologia e da soberania alimentar.

A agroecologia tem como princípios a negação do agrotóxico e a não dependência de insumos externos, ou seja, tudo que seja necessário à produção tem que ser retirado da unidade produtiva. Além disso, a preservação dos recursos naturais necessários para a própria otimização e perpetuação do agroecossistema, o retorno financeiro adequado ao camponês e a inserção dos produtos no mercado consumidor pelo viés do alimento saudável e do comércio justo também são elementos importantes que merecem ser destacados e que dizem respeito à filosofia da agroecologia (CAPORAL, 2011; ALTIERI, 2004). Uma questão importante foi levantada por Primavesi (2002, p. 7), que faz a diferenciação entre a agricultura agroecológica e a agricultura apenas orgânica, e nos adverte: 
[...] na orgânica você trabalha pelas normas, e as normas não fazem nada mais que trocar um agente químico por um orgânico [...]. O grande erro da agricultura orgânica é que, primeiro, continua com toda a visão factorial, fator por fator, continua combatendo no lugar de evitar. No final a melhora que se consegue é muito pouca.

Desse modo, a agroecologia está livre não só dos insumos químicos, como também das amarras econômicas e sociais do agronegócio, e, ao unir filosofia e prática em prol de uma agricultura capaz de diminuir as contradições provocadas pelo capital, tanto no campo quanto na cidade, e de assegurar a soberania alimentar, configura-se como resistência ao paradigma dominante que move a lógica produtivista.

Como já mencionamos, das experiências agroecológicas existentes na Paraíba, o grupo que deu origem à Ecovárzea é o pioneiro, tanto na transição agroecológica quanto nos formatos organizativos de comercialização. Essa afirmativa ganha notoriedade a partir dos depoimentos de camponeses da Ecovárzea, que antes de serem assentados da reforma agrária foram submetidos ao trabalho no corte da cana. Indagamos sobre quais foram as mudanças ocorridas na vida dos entrevistados, passados quase 20 anos de seu ingresso na condição de assentado e mais de 10 anos de comercialização na Feira que acontece no Campus I da UFPB. Nascimento (2011) nos diz que: "Antes de me assentar vivia doente, com tosse e cansaço. Não sei... mas acho que só podia ser do veneno e da canseira também, né?" (informação verbal) ${ }^{5}$.

Segue o relato de Melo (2011):

A gente vivia na agricultura patronal, a agricultura canavial,
a gente trabalhava na indústria da cana-de-açúcar, o
aprendizado era assim... muito pouco, porque aquilo que a
gente tinha praticado naquele momento era a experiência
deles no cultivo da cana... Meu pai não tinha muito que falar,
porque o que ele aprendia era aquela repressão de usina e a
gente não tinha aquela experiência muito com a agricultura

${ }^{5}$ Entrevista com o camponês Geraldo do Nascimento, do assentamento Padre Gino, realizada na Feira Agroecológica da UFPB, março de 2011. 
familiar, porque a agricultura familiar pra mim ela veio de 12 anos pra cá (informação verbal) ${ }^{6}$.

Segue o relato de Lima (2011):

Eu era boia fria, trabalhava alugado pra dar a escola das crianças que eu já tinha quatro filhos [...]. O que eu produzia era pra família, pro consumo e o que sobrava a gente vendia aos atravessadores pelo preço que eles queriam, e, às vezes, não recebia. Era uma humilhação. Hoje eu tenho a minha terra, tenho o meu gado, eu tenho os meus carneiros, tenho minhas galinhas, eu tenho a minha vida, lá quem manda sou eu (informação verbal) ${ }^{7}$.

Podemos perceber, a partir dos relatos, as péssimas condições de trabalho as quais eram submetidos; as estratégias utilizadas pelas usinas para garantir a submissão desses trabalhadores; como também a satisfação do camponês com a melhoria na qualidade de vida, avaliada a partir de elementos como as relações de trabalho e liberdade.

\section{A CERTIFICAÇÃO PARTICIPATIVA: UMA ESTRATÉGIA DE RESISTÊNCIA E REPRODUÇÃO CAMPONESA}

Um processo de certificação, de modo geral, busca oferecer garantia aos consumidores sobre a natureza de determinado produto. De acordo com Nassar (1999), a certificação possui dois principais objetivos, que são: agir como um instrumento para as empresas gerenciarem e garantirem internamente o nível de qualidade de seus produtos e informar e garantir aos consumidores que os produtos certificados possuem os atributos procurados, intrínsecos aos mesmos. Na agricultura não é diferente, e o mercado convencional de produtos orgânicos utiliza o mecanismo da certificação para garantir sua procedência e qualidade.

${ }^{6}$ Entrevista com o camponês Assis Barbosa de Melo, do assentamento Rainha dos Anjos, realizada na Feira Agroecológica da UFPB, junho de 2011.

7 Entrevista com o camponês Luiz Damásio de Lima, do assentamento Padre Gino, realizada da Feira Agroecológica da UFPB, junho de 2011. 
Os organismos que elaboram normas de certificação internacionalmente aceitas, e que se relacionam com a produção orgânica, são: a International Federation of Organic Agriculture Movements (Ifoam); o Good Agricultural Practices EuropGap; o ISO 65; e o Codex Alimentarius. Embora as diretrizes da produção e da certificação sejam internacionalizadas, cada país possui normas próprias, pois é necessária uma adaptação às diferentes condições de produção.

A certificação do alimento orgânico no Brasil foi prevista pela Lei dos Orgânicos (10.831/2003), instituída pela Lei 6.323 de 27 de dezembro de 2007, e padronizada por instruções normativas derivadas das referidas legislações. As certificadoras precisam estar registradas no Instituto Nacional de Metrologia, Qualidade e Tecnologia (Inmetro) e no Ministério da Agricultura Pecuária e Abastecimento (Mapa). As certificadoras autorizadas a funcionar no Brasil são: o Instituto Biodinâmico de Certificações (IBD); a Ecocert Brasil; a IMO CONTROL do Brasil; o Instituto de Tecnologia do Paraná (Tecpar); a Organização Internacional Agropecuária (OIA); e, desde recentemente, o Instituto Nacional de Tecnologia (INT).

A fiscalização realizada pelas certificadoras é feita por meio de auditorias às áreas de produção, que podem ser feitas tanto com agendamento quanto aleatórias, e seguem os critérios estabelecidos pela Lei 10.831, e pela Lei 6.323 de 27 de dezembro de 2007. De maneira geral, fiscalizam a origem dos insumos, as condições do solo, dos recursos hídricos, e principalmente o não uso de agrotóxico na produção, tendo como obrigatoriedade a renovação do selo todos os anos.

$\mathrm{Na}$ perspectiva economicista, passou-se a conceber a agricultura orgânica pelas "regras" ditadas pelo mercado, entre elas está a da certificação, sendo o alto custo dos serviços oferecidos por essas empresas especializadas o ponto de maior estrangulamento para a participação da agricultura camponesa nesse sistema de certificação. Assim,

[...] para a realidade da agricultura familiar nos países do Sul, o preço cobrado pelo serviço da certificação os impede de entrar neste jogo. Ao preço cobrado pelas certificadoras se soma o fato de muitos compradores do Norte exigirem determinados certificados, obrigando os exportadores do Sul 
a contratarem o serviço de mais de uma certificadora, algumas vezes chegando a 4 ou 5 diferentes certificações para a mesma área, levando os custos a patamares insustentáveis para os produtores (MEIRELLES, 2003, p. 2).

Percebe-se que, além da crítica relacionada aos altos preços praticados pelas certificadoras, existe também aquela relacionada à indiferença da metodologia da certificação por auditoria, ou seja, a inspeção é feita por terceiros, o que não estimula a autonomia camponesa de conferir credibilidade ao produto orgânico.

O fato de a inspeção ser realizada por pessoas e estruturas externas à comunidade não cria um processo de empoderamento da família agricultora ou da comunidade, o que dificulta o surgimento de formatos organizativos que poderiam ser desenhados para atender também a essa necessidade. $A$ premissa de suspeição dos agricultores, intrínseca a essa lógica de certificação, constitui outra desvantagem desse processo, já que causa desconforto a quem busca a certificação e não contribui com o resgate da autoestima dos agricultores e agricultoras envolvidos (MEIRELLES, 2003, p. 2).

As condições colocadas pela metodologia da certificação tradicional remetem à necessidade de se pensar uma certificação com características mais sociais e participativas. A resistência ao formato de certificação instituído pelas certificadoras advém do entendimento de que "o mercado e suas regras não são uma realidade absoluta, à qual devemos nos moldar, mas, sim, um conjunto de relações historicamente construídas, que tanto podem dominar como ser dominadas por outras práticas sociais" (MEIRELLES, 1998, p.1), e é esse o fundamento da certificação participativa proposta pela Agroecologia.

Nessa perspectiva surgem os Sistemas Participativos de Garantia (SPGs), encontrados principalmente na Europa e América Latina, cuja aliança entre produção e consumo é o ponto forte da certificação. A confiança entre os envolvidos no processo de certificação (consumidores, técnicos e camponeses) é oriunda da ação coletiva e da troca de saberes realizada tanto nas Feiras quanto nas áreas de produção. Desse modo, Padilla (2008, p.65) afirma que 
En este tipo de productos, el mecanismo de garantía más simple es el establecimiento de una relación directa o personal entre la producción y el consumo. Es la vía adoptada por diversas experiencias de consumo directo de productos ecológicos, donde se establece una relación estrecha entre ambos. En estos casos, la garantía del origen ecológico de los productos intercambiados es directa, a través de relaciones personales de conocimiento mutuo.

Na metodologia dos SPGs, a garantia da certificação é firmada por

[...] los grupos de productores, en colaboración con otros actores (consumidores, ONG,...) establecen un sistema propio de verificación, en el que participan todos los actores implicados en el proceso de producción y consumo (PADILLA, 2008, p. 69).

Assim, a metodologia dos SPGs fundamenta-se na organização social com enfoque na confiança, descentralização e democracia, onde os envolvidos possuem o mesmo poder de decisão e a rede da certificação se transforma numa verdadeira estrutura de trocas de saberes, com forte caráter pedagógico por meio do qual os camponeses fortalecem as condições de sua existência.

Recentemente, o SPG para produção orgânica foi reconhecido pelo Mapa, por meio do Decreto-Lei 6.323 de 27 de dezembro de 2007. Essa ação foi reivindicada principalmente pela Rede Ecovida, sendo responsável por sistematizar os critérios instituídos para a normatização. Assim, a certificação da produção orgânica camponesa a partir de uma metodologia participativa se constitui como uma conquista política dos movimentos sociais e das ONGs, organizada a partir de eventos específicos de agroecologia e reivindicada junto ao poder público. 


\section{A CERTIFICAÇÃo PARTICIPATIVA E SOCIAL DA ECOVÁRZEA}

Ao longo da pesquisa de mestrado, após a revisão bibliográfica e a análise crítica da questão agrária brasileira, suas disputas territoriais e estratégias de reprodução do campesinato, como as Feiras Agroecológicas e a certificação participativa, estudamos o caso da certificação participativa e social da Ecovárzea. A pesquisa objetivou conhecer a metodologia e identificar elementos fundamentais para o fortalecimento do território camponês. Para tal, foram seguidos os seguintes passos: análise da legislação vigente que trata do tema; análise de relatórios de projetos de extensão universitária que ajudaram a conduzir a certificação em discussão; visitas às entidades da sociedade civil que apoiam o projeto das Feiras, a exemplo da (CPT), assim como a órgãos oficiais como o Mapa; visitas à Feira Agroecológica da UFPB, assim como a algumas unidades produtivas; entrevista semiestruturada dirigida aos camponeses e parceiros da certificação da Ecovárzea; participação nas assembleias da Ecovárzea que pautaram a certificação; participação nos encontros políticos que pautaram a certificação participativa na Paraíba. Por último foi sistematizado e analisado de forma critica o conteúdo levantado.

Desde o surgimento do projeto da Feira da UFPB, em 2001, os camponeses da Ecovárzea se preocupam em garantir aos consumidores e parceiros a qualidade agroecológica dos produtos comercializados. Assessorados pela CPT e inspirados pelo processo organizativo da Rede Ecovida, desde o início, já adotavam algumas práticas e critérios com o objetivo de garantir a qualidade dos seus produtos. Os critérios de produção foram estabelecidos desde a implantação da Feira, porém só foram registrados em 2005 com a formalização da associação, a criação do estatuto, do regimento interno e do Conselho de Ética, os quais, entre outras atribuições, são responsáveis por assegurar a procedência agroecológica dos produtos comercializados.

O estatuto e o regimento interno contemplam as boas práticas que garantem o cumprimento dos regulamentos técnicos de manejo agroecológico, bem como o respeito à biodiversidade e ao comércio justo, e 
preveem punições, como o afastamento do produtor da Feira, quando constatado o não cumprimento do previsto. De acordo com o estatuto, é o Conselho de Ética que monitora junto à área de produção o não uso de agrotóxico, e também acompanha de perto a transição para uma produção agroecológica. O camponês interessado em ingressar no processo precisa participar das reuniões e intercâmbios por no mínimo dois anos para ser inserido no grupo da comercialização. As visitas do Conselho de Ética também tem o intuito de contribuir para a melhoria da produção do camponês visitado.

De acordo com o estatuto da Associação, Capítulo IV, Seção IV, Artigo 170, compete ao Conselho de Ética:

- Zelar pelos princípios da produção orgânica, agroecologia e pelo respeito interpessoal e outros;

- Informar à Coordenação Executiva sobre irregularidades ocorridas e constatadas para que sejam aplicadas as medidas devidas de acordo com o Regimento Interno;

- Zelar pelo cumprimento do Regimento Interno.

O sistema de auditoria é feito através de visitas periódicas às propriedades e ao local de comercialização, tanto pelos consumidores e técnicos quanto pelo Conselho de Ética da Feira - que é composto por três associados, escolhidos por eleição direta a cada dois anos. Não existe um calendário de visitas nem um esquema logístico formalizado, é apenas sugerida a visita do Conselho de Ética uma vez ao ano em cada área produtiva. Em relação às visitas dos consumidores, constatamos através de entrevistas que as mesmas são realizadas de acordo com o combinado entre eles e os camponeses.

As assembleias mensais da Ecovárzea funcionam também como momentos de troca de experiências e acompanhamento da produção. A partir de conversas, a coordenação da Feira questiona os produtores sobre suas práticas agrícolas, e propõe ou encaminha a melhor solução para os problemas relatados. 
A busca em formalizar e aperfeiçoar o processo de certificação da Ecovárzea surgiu logo após o início da Feira na UFPB, por uma preocupação dos próprios camponeses em garantir a credibilidade perante a comunidade universitária. Foi então que, preocupados em atestar e aperfeiçoar os mecanismos de garantia dos seus produtos, os camponeses procuraram em 2003 o Grupo de Ergonomia Agrícola e Gestão Ambiental (GEA), vinculado ao Centro de Tecnologia da UFPB, para juntos pensarem numa alternativa de certificação da Feira (ADISSI, 2006).

A partir da demanda colocada pela Ecovárzea, o GEA/UFPB, em parceria com o Departamento de Geociências/UFPB, elaborou o projeto intitulado: Feira Agroecológica da UFPB: certificação social e revitalização, que obteve financiamento do CNPq através do edital MDA/MCT/CTAGRO/CNPq 22/2004. O objetivo do projeto era o de promover a certificação da Feira através de uma metodologia participativa, que atendesse às expectativas dos consumidores e às possibilidades dos produtores. Durante o primeiro ano do Projeto, por meio de reuniões e aplicação de questionários, os consumidores da Feira Agroecológica da UFPB estabeleceram os seguintes critérios para certificação da produção da Ecovárzea:

1) não utilização de agroquímicos na produção, comprovada através de análise de resíduos;

2) boas condições sanitárias, comprovadas através de análise bioquímica;

3) rotulagem dos produtos manipulados contendo composição e valor nutritivo;

4) livre acesso dos consumidores às áreas de produção.

As figuras 1 e 2 retratam alguns momentos de planejamento e mobilização. 


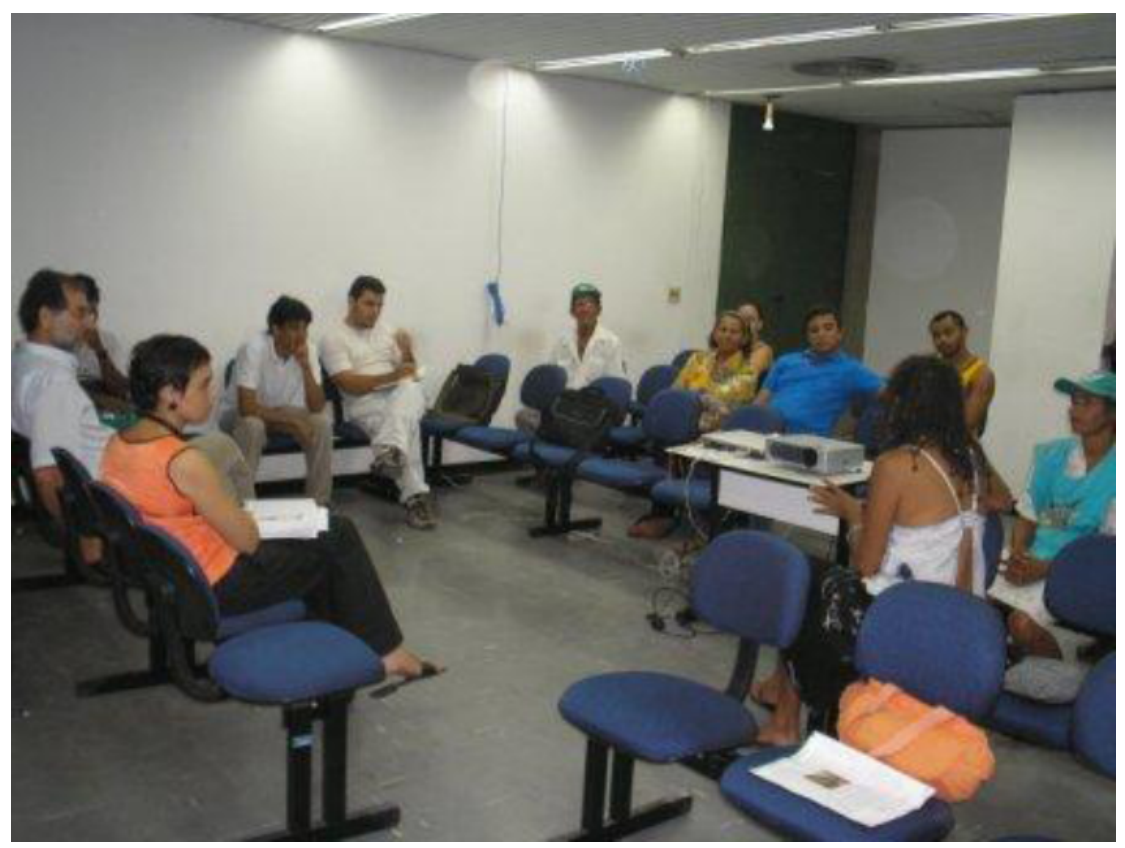

Figura 1: Reunião para planejamento da certificação da Ecovárzea. Estavam presentes camponeses, consumidores, técnicos, estudantes e professores universitários. Acervo GEA, 2005.

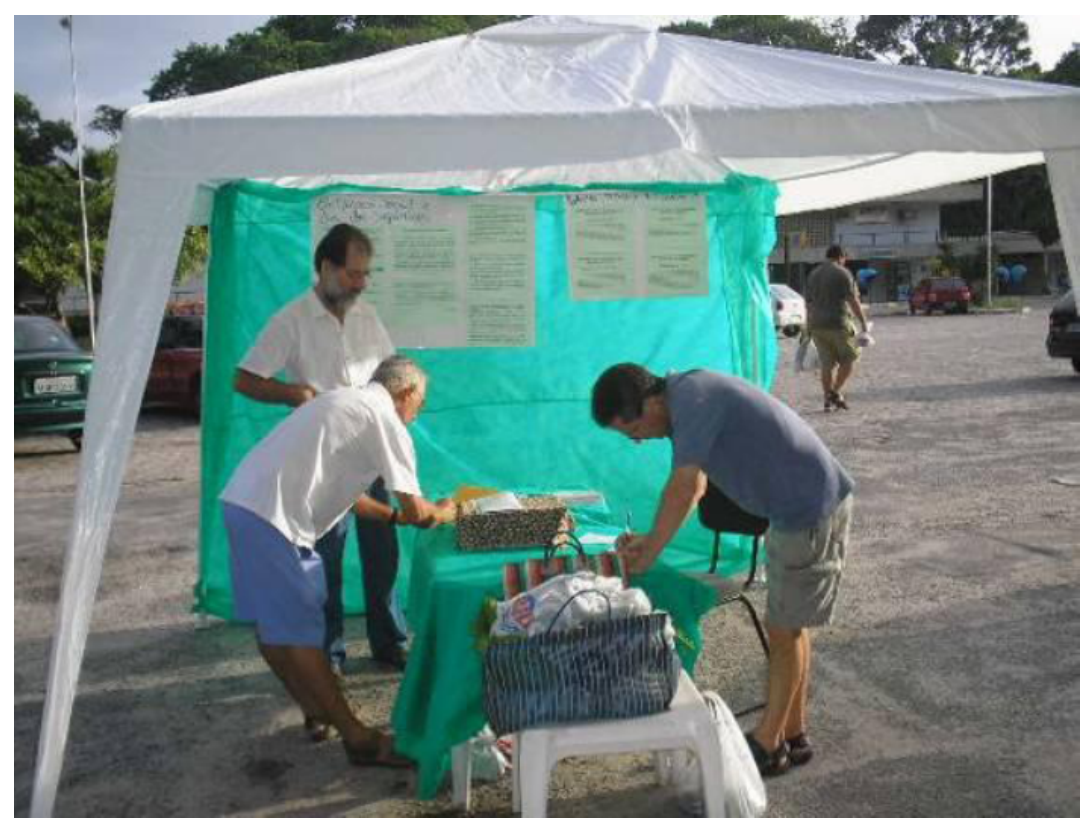

Figura 2: Pesquisa acerca dos critérios de certificação. Acervo GEA, 2005.

Após essa primeira etapa, houve um debate interno entre a diretoria da Ecovárzea e os membros do projeto sobre a importância de se cumprir (ou não) o solicitado pelos consumidores e a melhor maneira de se obter os 
critérios sugeridos. A partir de então, trabalhou-se em conjunto para atingir os critérios estabelecidos e consolidar o laço de respeito e confiança que caracteriza a relação entre produtor e consumidor na Feira. Na gestão do projeto que iniciou o processo, foram cumpridos os critérios 1 e 2 . Para isso, foram realizadas análises laboratoriais que comprovaram a ausência de resíduos de agrotóxicos e as boas condições sanitárias dos produtos. As amostras foram retiradas de todas as barracas da Feira, e contemplaram três produtos: alface, cenoura e tomate. Tais amostras foram encaminhadas para o Laboratório de Análise de Resíduos de Agrotóxico (Labtox) vinculado ao Instituto de Tecnologia de Pernambuco (Itep). Os resultados indicaram amostras isentas de resíduos de agrotóxicos.

Apesar de iniciados, os critérios 3 e 4 não foram concluídos na vigência do referido projeto de extensão, o que motivou os integrantes do GEA e os camponeses da Ecovárzea a construir um segundo projeto, intitulado Feira Agroecológica da UFPB, que também recebeu financiamento do CNPq, através do edital MCT/CNPq/MDA/SAF/MDS/SESAN 36/2007.

Na vigência do segundo projeto, o critério 3 foi cumprido através da confecção de vários rótulos para os produtos beneficiados comercializados na Feira, entre biofertilizantes, adubos e comidas prontas. Os rótulos das comidas prontas contêm informações nutricionais, peso, data de fabricação, contato do produtor e a porcentagem orgânica de cada produto, pois alguns ingredientes utilizados não têm garantia de serem orgânicos, uma vez que os produtores os compram no mercado comum, como é o caso da farinha de trigo. Os referidos rótulos foram confeccionados em grande quantidade e a matriz entregue à diretoria da associação, para que, quando houvesse necessidade, fossem novamente impressos.

O critério 4, que diz respeito às visitas de campo ou "auditorias" periódicas, também foi cumprido. Contudo esse é o critério que apresenta maior fragilidade, pois não existe calendário de visita regular, sendo realizado de forma aleatória por alguns consumidores que combinam com os camponeses tais visitas.

Para além da efetivação dos critérios 3 e 4, foi realizada pelo segundo projeto uma outra análise laboratorial para firmar a confiança entre consumidores e produtores. As análises foram realizadas pelo Labtox e 0 
resultado foi novamente negativo para o conjunto de substâncias ativas de agrotóxicos.

Portanto, a certificação participativa da Ecovárzea se estabeleceu a partir de critérios e padrões de qualidade eleitos pelos consumidores e posterior discussão e ajuste da produção e da comercialização com o apoio da assessoria técnica. O grupo define a sua certificação como sendo uma certificação social de metodologia participativa.

\section{O RECONHECIMENTO DA CERTIFICAÇÃO PARTICIPATIVA PELO ESTADO E SUA IMPORTÂNCIA SOB A ÓTICA DO CAMPESINATO}

Durante a execução do segundo projeto de extensão que apoiou a certificação da Ecovárzea, os SPGs foram reconhecidos pelo órgão regulador da qualidade orgânica, o Mapa, o que possibilitou, após algumas adequações, o enquadramento legal de todo o processo de certificação realizado.

A regulação específica (Lei 10.831 de 23 de dezembro de 2003; Decreto 6.323 de 27 de dezembro de 2007; Instrução Normativa 64 de 18 de dezembro de 2008) possibilita a garantia da qualidade orgânica por três mecanismos distintos: 1) Os Organismos de Conformidade Social (OCS), que possibilitam o funcionamento de ponto de venda direta de produtos orgânicos, no qual se enquadram as Feiras Agroecológicas; 2) A metodologia convencional, realizada por empresas especializadas em certificação, cuja metodologia já foi brevemente descrita; 3) A certificação participativa, que diz respeito ao SPG, e que possibilita a venda a mercados privados.

Assim, para a venda direta da produção agroecológica, a legislação brasileira, ao reconhecer o pacto realizado entre produtores e consumidores como atestado de qualidade, abriu uma exceção na obrigatoriedade de selos para garantir a procedência de produtos orgânicos. Exige-se, porém, o cadastro da entidade que promove a Feira junto ao Mapa, estando as áreas 
de produção sujeitas, a partir daquele momento, a uma fiscalização do órgão oficial. Com isso, os agricultores passam a fazer parte do Cadastro Nacional de Produtores Orgânicos (CNPO).

O cadastro da Ecovárzea como OCS foi realizado através do empenho de todo o grupo envolvido no projeto, impulsionado principalmente por um compromisso social com a causa. Após o cadastramento dos camponeses e da Ecovárzea como OCS, e protocolado o termo de compromisso firmado pela Ecovárzea, que garante a qualidade orgânica dos produtos, os camponeses receberam uma "declaração de cadastro de produtor vinculado à OCS" (figura 3).

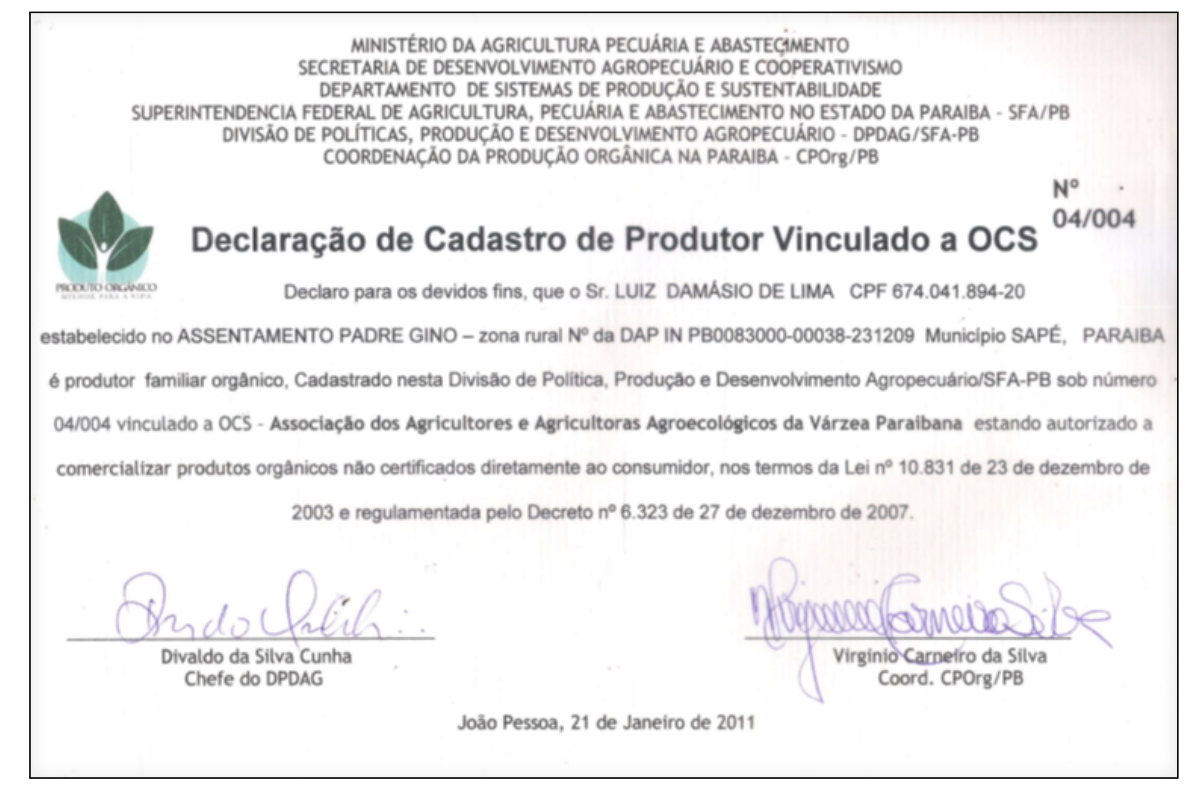

Figura 3: Declaração de Cadastro de Produtor vinculado a OCS. Fonte: MAPA Comissão de Orgânicos da Paraíba.

Na Paraíba, até a finalização da nossa pesquisa, foram cadastradas junto ao Mapa 12 entidades como OCS, distribuídas em 10 municípios, como se vê no mapa 3 . 


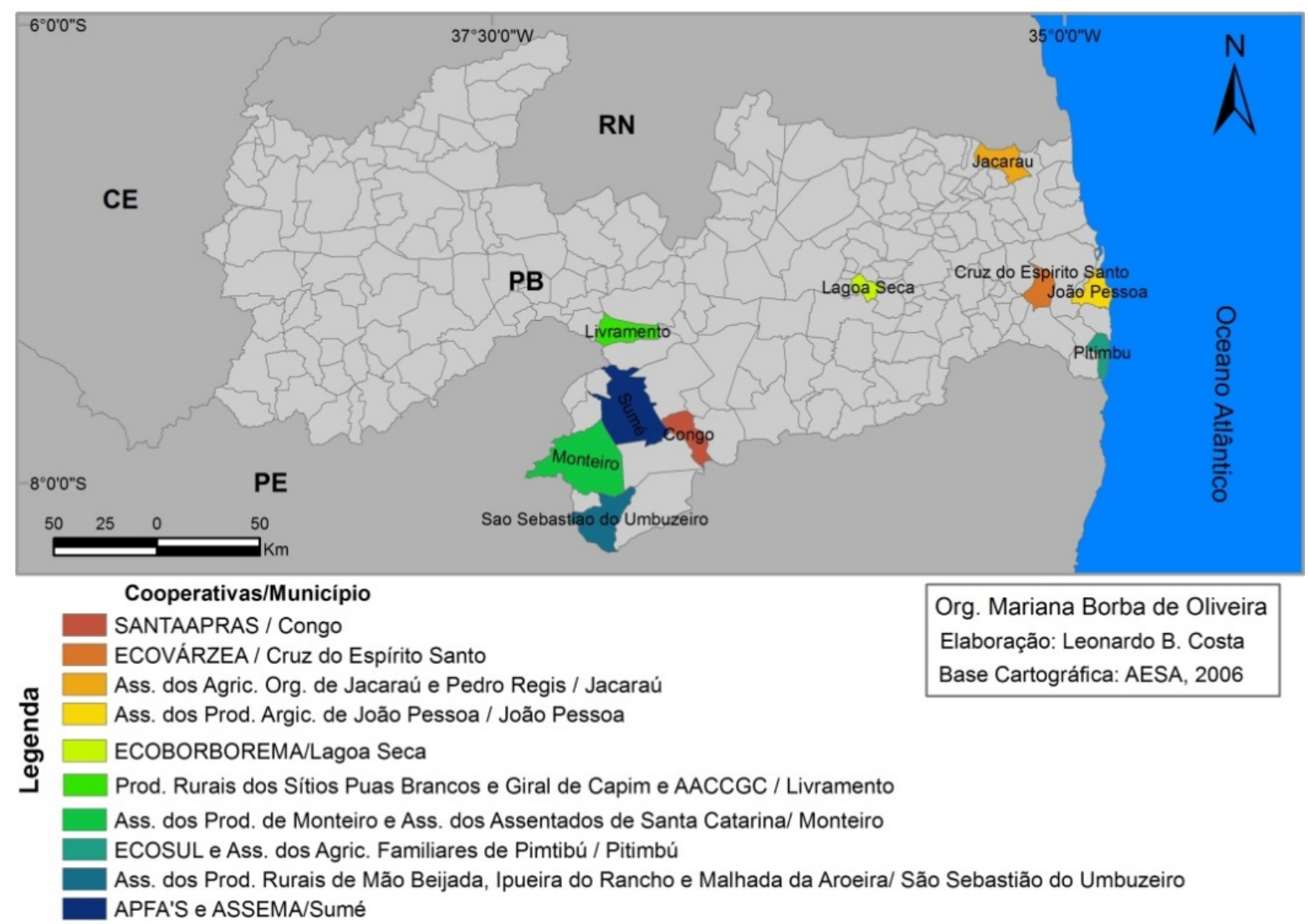

Mapa 3: Localização dos Organismos de Conformidade Social (OCS) cadastrados junto ao Mapa na Paraíba.

A viabilidade em se formalizar o SPG dos produtos da agricultura familiar (inclusive os da Ecovárzea), que possibilitaria a aquisição do selo de produção orgânica e a autorização de comercializar em qualquer mercado, foi discutida na oficina "Formação de multiplicadores sobre Regularização de Grupos de Agricultores via Sistemas Participativos de Garantia Organizações de Controle Social Frente à Legislação Orgânica", oferecida pelo Mapa às organizações camponesas do estado da Paraíba. O principal objetivo da oficina foi esclarecer as dúvidas das organizações ligadas à agroecologia frente à legislação orgânica e a regularização das entidades que produzem orgânicos. Desta forma, o objetivo era a formação de multiplicadores do conhecimento acerca do controle social da produção orgânica por Venda Direta ou SPG.

Durante o evento, foi identificado um fator de suma importância para nossa análise. Foi levantada a seguinte questão pelos camponeses e por entidades parceiras, como a associação Agricultura Familiar e Agroecologia (AS-PTA) e a UFPB: "para quem estamos certificando os nossos produtos?" 
e, posteriormente: "em qual canal de comercialização estamos interessados?". A maioria das pessoas presentes eram camponeses que comercializam seus produtos por meio de Feiras e em mercados institucionais (Programa de Aquisição de Alimentos - PAA e Programa Nacional de Alimentação Escolar - $\mathrm{PNAE}^{8}$ ), e muitas vezes, devido às dificuldades inerentes à prática da agricultura camponesa, não conseguem dar conta da demanda estabelecida por esses mercados. As indagações deixaram clara a percepção dos mesmos sobre a agroecologia, que possibilita retornos financeiros aos camponeses em consonância com um projeto maior, definido por eles como a satisfação e saúde de um número maior de pessoas, ou seja, um projeto que assegure a soberania alimentar de quem produz e de quem consome. Portanto, a possibilidade de abertura do mercado privado de orgânicos foi considerada algo fora dos valores estabelecidos pelos camponeses que produzem tendo como base a agroecologia no estado da Paraíba.

Ficou entendido que a prioridade para os camponeses envolvidos no projeto da agroecologia no estado da Paraíba é expandir sua comercialização através da Venda Direta (as Feiras Agroecológicas, os ônibus itinerantes $e$ os pontos fixos geridos pelas associações e cooperativas de agricultores), e dos mercados institucionais (PAA e PNAE) e assim beneficiar mais famílias.

\section{CONSIDERAÇÕES FINAIS}

A pesquisa evidencia que o campesinato desenvolve metodologias próprias para garantir a qualidade dos produtos vendidos assim como um comércio justo, o que tem sido reconhecido pela sociedade civil e pelo governo. Os camponeses que fazem parte da Ecovárzea estão na "contramão" das tendências homogeneizadoras de certificação e comércio

8 O PAA foi instituído pelo artigo 19 da Lei Federal 10.696/2003. O PNAE destina no mínimo $30 \%$ dos recursos para as compras diretas da agricultura familiar. 
de produtos orgânicos. Nessa perspectiva, para a Ecovárzea, "o mundo melhor" já existe, e é fruto da valorização do ser humano no decorrer de uma mudança paradigmática de produção e consumo.

Os camponeses em questão conseguem garantir aos consumidores a qualidade agroecológica da produção, ao mesmo tempo em que contribuem para melhorar a produção uns dos outros, com o apoio dos consumidores e demais parceiros. É um processo baseado em troca de experiências e confiança, sem hierarquias e altos custos, e por isso o grupo que organizou a certificação participativa da Ecovárzea acredita que um novo paradigma de produção e consumo só pode ser implantado com o compromisso e a participação de quem produz e de quem compra.

Conclui-se que a agroecologia representa uma alternativa de redução das contradições provocadas pela modernidade, capaz de melhorar a relação sociedade $x$ natureza no campo e também na cidade, fortalecer a territorialidade camponesa dos assentamentos rurais, contribuir para um projeto de soberania alimentar do campo e da cidade, e se constitui como instrumento de troca de saberes e empoderamento popular. Considera-se que as dificuldades enfrentadas pelo grupo estudado não comprometem a continuidade e o fortalecimento dessa experiência de resistência camponesa, capaz de promover um desenvolvimento local pautado na agroecologia.

A utopia de uma sociedade justa e de uma liberdade vinculada à territorialidade camponesa é o que move essa experiência inserida num contexto espacial e histórico de domínio do agronegócio canavieiro, a Zona da Mata paraibana.

\section{BIBLIOGRAFIA}

ADISSI, Paulo J. Relatório Final do Projeto de Extensão: Feira Agroecológica do Campus I da UFPB: certificação social e revitalização. CNPq/Edital MDA/MCT/CT-AGRO/CNPq 22/2004. João Pessoa, 2006.

ALTIERI, Miguel. Agroecologia: a dinâmica produtiva da agricultura sustentável. 4.ed. Porto Alegre, RS: Ed. da UFRGS, 2004. 
ANDRADE, Manoel Correia. A terra e o homem do Nordeste. 5.ed. São Paulo, SP: Atlas, 1986.

BRASIL, Presidência da República. Lei no 10831 de 23 de dezembro de 2003. Dispõe sobre a agricultura orgânica e dá outras providências. Diário Oficial da União, Brasília, DF, 24 dez. 2003.

. Decreto no 6.323 de 27 de dezembro de 2007. Regulamenta a Lei no 10.831, de 23 de dezembro de 2003, que dispõe sobre a agricultura orgânica, e dá outras providências. Diário Oficial da União, Brasília, DF, 28 dez. 2007.

- Ministério da Agricultura Pecuária e Abastecimento. Instrução Normativa no 64 de 18 de Dezembro de 2008. Dispõe sobre o regulamento técnico para os sistemas orgânicos de produção animal e vegetal. Diário Oficial da União, Brasília, DF, 19 dez. 2007. Seção 1.

CAPORAL, Francisco Roberto. Agroecologia: uma nova ciência para apoiar a transição a agriculturas mais sustentáveis In: CAPORAL, F.R.; AZEVEDO, E.O. (orgs.). Princípios e Perspectivas da Agroecologia. Instituto Federal de Educação, Ciência e Tecnologia do Paraná - Educação a Distância, 2011. Disponível em: < http://wp.ufpel.edu.br/consagro/files/2012/03/CAPORAL-Francisco-

Roberto-AZEVEDO-Edisio-Oliveira-de-Princ\%C3\%ADpios-e-Perspectivas-daAgroecologia.pdf>. Acesso em: 20 jan. 2012.

COSTA NETO, C. P. L. Agricultura familiar camponesa: territórios em questão. Sapiência Informativo Científico da FAPEPI. Teresina, v. 25, ano VI p. 6, 2010. Edição Especial.

DEAN, Warren. A Ferro e Fogo. São Paulo: Companhia das Letras, 2002.

ECOVÁRZEA. Estatuto da associação dos agricultores e agricultoras agroecológicos da várzea paraibana - Ecovárzea paraibana. Cruz do Espírito Santo - PB, 2005.

FERNANDES, Bernardo Mançano. MST - Formação e Territorialização. Editora Hucitec, 1996.

GALEANO, Eduardo. As veias abertas da América Latina. Ed. 26. Rio de Janeiro: Paz e Terra SA, 1988. 307p.

MARCOS, Valéria et al. Feira Agroecológica do Campus I da UFPB: certificação social e revitalização. In: III Simpósio Nacional de Geografia Agrária, 2005, Presidente Prudente. Anais... Presidente Prudente: UNESP, 2005.

MARCOS, V.; FABRINI, J. E. . Os camponeses e a práxis da produção coletiva. 1. ed. São Paulo: Expressão Popular, 2010. 149p.

MARTINS, José de Souza. Os Camponeses e a Política no Brasil. 4. ed. Petrópolis: Vozes, 1981. 184p. 
O cativeiro da terra. 9. ed. São Paulo, SP: Contexto, 2010. 282p

MARX, Karl. Introdução à crítica da Economia Política. In: MARX, Karl. Para a crítica da economia política do Capital: o rendimento e suas fontes. Trad. Edgard Malagodi. São Paulo: Nova Cultural, 1999.

MEDAETS, Jean Pierre; FONSECA, Maria Fernanda de A. C. Produção orgânica: regulamentação nacional e internacional. Brasília: Ministério do Desenvolvimento Agrário, NEAD, 2005.

MEIRELLES, Laércio. Agricultura Orgânica e mercado - algumas considerações. Centro Ecológico Ipê Serra Litoral Norte: Assessoria e Formação em Agricultura Ecológica. Ipê - RS, 1998. Disponível em:< http://www.centroecologico.org.br/artigo_detalhe.php?id_artigo=4 $>$.

Acesso em: 5 mar. 2012.

A Certificação de Produtos Orgânicos - caminhos e descaminhos. Centro Ecológico Ipê Serra Litoral Norte: Assessoria e Formação em Agricultura Ecológica. Ipê-RS, 2003. Disponível em: $<$ http://www.centroecologico.org.br/artigo_detalhe.php?id_artigo=3>.

Acesso em: 5 mar.2012.

MENDONÇA, Marcelo Rodrigues; THOMÁZ JR, Antônio; RIBEIRO, Dinalva DoniZete. A modernização da agricultura e os impactos sobre o trabalho. Revista Scripta Nova - Revista Eletrônica de Geografia y Ciências Sociales, Barcelona, v.6, n.119, 2002. Disponível em: < http://www.ub.edu/geocrit/sn/sn119-44.htm\#**>. Acesso em: 5 mar.2012.

MOREIRA, Emília; TARGINO, Ivan. Capítulos de Geografia Agrária da Paraíba. João Pessoa, PB: Ed.Universitária/UFPB, 1997.

NASSAR, A. M. Certificação no agribusiness. In: IX Seminário Internacional Pensa de Agribusiness, Águas de São Pedro, 1999. Anais... São Paulo: USP. PENSA, 1999. 79.

OLIVEIRA, Ariovaldo Umbelino. Modo capitalista de produção e agricultura. 3.ed. São Paulo-SP: Ática, 1990.

\section{Modo de Produção Capitalista, Agricultura e Reforma}

Agrária. 1 ed. São Paulo: Labur, FFLCH, 2007.

OLIVEIRA, Mariana B. O Assentamento Padre Gino - PB e a Feira Agroecológica do Campus I da UFPB. Monografia de Bacharelado apresentada no Departamento de Geociências da Universidade Federal da Paraíba - UFPB. João Pessoa, 2006.

Certificação Participativa e Agroecologia: Processos de Organização e Resistência Camponesa na Mata Paraibana. Dissertação de Mestrado defendida no Programa de Pós Graduação em Geografia da Universidade Federal da Paraíba - UFPB. João Pessoa, 2012. 
PADILHA, M. C. Hacia un sistema participativo de garantía para la producción ecológica en Andalucía. Tese de Doutorado apresentada na Universidade de Córdoba, Córdoba / Espanha, 2008. Disponível em: $<$ http://base.socioeco.org/docs/abre_fichero.pdf>. Acesso em: 2 dez. 2011.

PAULINO, Eliane Tomiasi; FABRINI, João Edmilson (Org). Campesinato e Territórios em Disputa. São Paulo: Expressão Popular. UNESP: Programa de Pós-Graduação em Geografia. 2008, 496p.

PAULINO, Eliane Tomiasi; ALMEIDA, Rosemeire Aparecida. Terra e território: a questão camponesa no capitalismo. São Paulo: Expressão Popular, 2010. 107p.

PAULINO, S.R; JACOMETI, W. A. Certificação na agricultura: possibilidades de diversificação e interação para o desenvolvimento da produção regional. Revista Desenvolvimento e Meio Ambiente, n. 14, p. 95-103. Ed. da UFPR, 2006.

PRIMAVESI, Ana Maria. O combate à pobreza é básico e depende da recuperação ambiental e da Agroecologia. Revista Agroecologia e desenvolvimento Rural Sustentável. v.3, n.4. Porto Alegre - RS, 2002. 